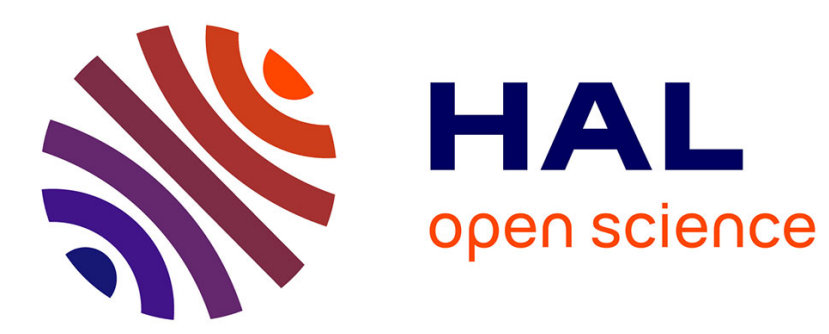

\title{
Development of new sticky and conducting polymer surfaces for MEMS applications
}

Jérôme Dejeu, Amélie Cot, Patrick Rougeot, Boris Lakard, Sophie Lakard, Michaël Gauthier

\section{- To cite this version:}

Jérôme Dejeu, Amélie Cot, Patrick Rougeot, Boris Lakard, Sophie Lakard, et al.. Development of new sticky and conducting polymer surfaces for MEMS applications. Synthetic Metals, 2021, 276, pp.116757. 10.1016/j.synthmet.2021.116757 . hal-03183884

\section{HAL Id: hal-03183884 \\ https://hal.science/hal-03183884}

Submitted on 20 Sep 2021

HAL is a multi-disciplinary open access archive for the deposit and dissemination of scientific research documents, whether they are published or not. The documents may come from teaching and research institutions in France or abroad, or from public or private research centers.
L'archive ouverte pluridisciplinaire HAL, est destinée au dépôt et à la diffusion de documents scientifiques de niveau recherche, publiés ou non, émanant des établissements d'enseignement et de recherche français ou étrangers, des laboratoires publics ou privés. 


\title{
Development of New Sticky and Conducting Polymer Surfaces for MEMS Applications
}

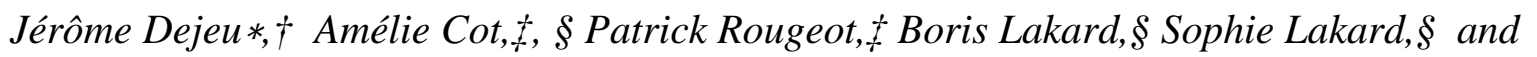
Michaël Gauthier $\neq$

†Université Grenoble Alpes, Département de Chimie Moléculaire, UMR-5250, 38041 Grenoble Cedex 9, France,

‡FEMTO-ST Institute, UMR CNRS 6174, Univ. Bourgogne Franche-Comté, 24 Rue Alain Savary, 25000 Besançon, France

§UTINAM Institute, UMR CNRS 6213, Univ. Bourgogne Franche-Comté, 16 Route de Gray, 25030 Besançon Cedex, France

Keywords: PANi, adhesion forces, micromanipulation, sticky surface, electropolymerisation

\begin{abstract}
The development of new surfaces, highly sticky and conducting, is a great challenge in the field of microdevices fabrication, and more precisely for the 3D assembly of microcomponents. Such surfaces were prepared by electrochemical deposition of polyaniline films. The films prepared from a phosphoric acid solution were more adhesive than the ones
\end{abstract}


obtained in other acids. Indeed, the adhesion of the polyaniline films prepared in $\mathrm{H}_{3} \mathrm{PO}_{4}$ was found to be high $(>1 \mu \mathrm{N})$ and stable in time, as shown by AFM force measurements. The adhesion properties were correlated with the morphology, thickness and roughness of the polyaniline films, and the electrodeposition conditions $\left(\mathrm{H}_{3} \mathrm{PO}_{4}\right.$ concentration and electrodeposition time) were optimized. The adhesion properties of this original polymer films were found to be similar to those of the best commercial glues. The conductivity of the polyaniline film was also demonstrated as well as the possibility for the polyaniline films to switch reversibly from a non-adhesive to an adhesive behavior. A wide range of applications, in the field of telecommunications, bioengineering, and more generally speaking MEMS (microelectromechanical systems) can be envisaged for these materials.

\section{Introduction}

3D integration is a rapidly emerging and revolutionary technology, which vertically stacks and interconnects multiple materials and functional components to form highly integrated micronano systems. 3D integration aims to increase density and functionality per volume using silicon vias, to shorten interconnect length, to improve electrical performances, to strongly reduce chips power consumption, to integrate various functional layers based on different optimized process nodes, and to reduce the cost of such devices. This 3D integration is expected to lead to an industry paradigm shift due to its tremendous benefits. Recent works mention the fact that the demand for 3D stacking equipment will certainly grow exponentially in the following years. ${ }^{1}$ One of the challenges of 3D integration is the electrical bonding between 3D thin stacked dies. Current bonding methods require the application of mechanical pressure (wire bonding) or the 
use of thermal cycles (Solder Ball Grid Array - BGA). ${ }^{2,3}$ Both technologies generate mechanical stresses on the dies which will be particularly critical for thin dies. ${ }^{4}$ These bonding technologies have therefore limitations that can affect the overall yield and cost of 3D devices. To offer an alternative to conventional bonding technologies, we are proposing a new bonding principle which acts without thermal cycle (assembly at room temperature) and without mechanical pressure. Our strategy has several benefits for bonding and assembly which should allow the rapid fabrication of reliable products, without thermal or mechanical damage. This strategy is based on the chemical functionalization of objects by polymers, and more particularly by thin conducting polymer films deposited by electrochemical polymerization. Among the many existing conducting polymers, polyaniline (PANi) ${ }^{5,6}$ is a material of choice which exhibits high conductivity at both room $^{7}$ and high temperature ${ }^{8,9}$ due to the possibility to dope polyaniline films by both oxidation and protonation. PANi films are generally prepared from mono- or diacids such as $\mathrm{HCl}^{6}{ }^{6} \mathrm{HNO}_{3}{ }^{10}$ or $\mathrm{H}_{2} \mathrm{SO}_{4},{ }^{11}$ but until now very few PANi films were prepared from a triacid such as $\mathrm{H}_{3} \mathrm{PO}_{4}$. This could be surprising since Boara et al. demonstrated that PANi films prepared from $\mathrm{H}_{3} \mathrm{PO}_{4}$ have interesting properties, especially they have a higher conductivity than PANi films prepared from $\mathrm{HCl}$ solutions under the same conditions. ${ }^{7}$ Moreover, this polymer has already been used to develop nano and microrobots, ${ }^{12,13}$ nanomaterials ${ }^{14}$ and smart systems. ${ }^{15}$ More recently PANi films were used to develop an acetic acid vapor sensor, ${ }^{16}$ to embed glucose oxydase $^{17}$ or in combination with poly(3,4ethylenedioxythiophene) (PEDOT) to enhance its electrochromic properties. ${ }^{18,19}$

So, in this work, PANi films were prepared electrochemically in the presence of phosphoric acid whose anions were used as dopants. This allowed us to evidence that the use of phosphoric acid leads to polyaniline films having very original and interesting adhesive properties compared 
to polyaniline films prepared in other electrolytic solutions, in addition to a high conductivity. Thanks to their remarkable adhesion and conduction properties, these electrodeposited polyaniline films are good candidates for applications in the field of 3D integration and microassembly.

\section{Material and Methods}

\subsection{Polymer electrodeposition}

Potentiostatic electropolymerization of polyaniline films was performed using a PGZ 301 potentiostat (Tacussel-Radiometer Analytical SA, France) controlled by a computer via VoltaMaster 4 software interface. A three-electrode electrochemical cell was used. The rectangular planar silica substrates (area: $1.0 \mathrm{~cm}$ x $0.5 \mathrm{~cm}$ ) used for polymer electrodeposition were obtained by cutting 100-oriented standard 4" silicon wafers (from Siltronix, B-doped, resistivity: $0.015 \pm 0.005 \Omega$.cm, thickness: $250 \pm 10 \mathrm{~mm}$ ). The reference electrode was a Saturated Calomel Electrode (SCE), XR110 model from Radiometer Analytical and the counter-electrode was a platinum sheet. All electrochemical experiments were carried out at room temperature $\left(25^{\circ} \mathrm{C}\right)$ and by chronoamperometry at $+2 \mathrm{~V} / \mathrm{SCE}$.

\section{$\underline{2.2 \text { Force distance measurements }}$}

Characterization of the pull-off force was performed with a commercial atomic force microscope (AFM: stand-alone SMENA scanning probe microscope NT-MDT). The experiments were done under a controlled environment with a laminar flow (humidity $30 \%$ and temperature $25^{\circ} \mathrm{C}$ ) on the Nanorol platform station. A rectangular silicon AFM cantilever with a stiffness of $0.3 \mathrm{~N} / \mathrm{m}$ was used for all experiments. As the objective of this work is to improve the reliability of micro-object manipulation, interactions have been studied between a micrometric 
sphere and a planar substrate. So, measurements were performed with a cantilever where a borosilicate sphere ( $\mathrm{r}_{1}=5 \mu \mathrm{m}$ radius) was glued in place of the standard AFM tip (Ref.: PT.BORO.SI.10, company Novascan Technologies, Ames, IA, USA). Ten measurements were done at different locations on the same sample with a driving speed of $200 \mathrm{~nm} / \mathrm{s}$.

\section{$\underline{2.3 \text { SIM and FIB experiments }}$}

A $30 \mathrm{keV} \mathrm{Ga}^{+}$focused ion beam (Orsay Physics Canion 31 FIB) was used to etch polymer films and their $\mathrm{Si} / \mathrm{SiO} 2$ substrate. After FIB irradiation, scanning ion microscopy (SIM) was used to observe the surface. The wafer was tilted and viewed at an incidence angle of $40^{\circ}$ or $35^{\circ}$ : the same ion beam, with a current limited to $30 \mathrm{pA}$, was used as a scanning probe to image the crosssection of the film. Different layers of materials can be clearly identified due to good material contrast in the ion-induced secondary electron image. The thickness of the $\mathrm{SiO}_{2}$ and polymer film can be measured directly from the cross-section view by compensating for the tilt angle, the apparent width of the layers being divided by the sinus of the tilt angle.

\section{$\underline{2.4 \text { Effort of tearing }}$}

The measurements are performed on substrates coated with a polymer film: two substrates are perpendicular and a third one is deposited perpendicular to the first two. The contact area between the substrates is perpendicular $\left(25 \mathrm{~mm}^{2}\right.$ on each side). The tests are carried to produce a force perpendicular to the plane formed by the substrates. The rod is held on a compliant system and is placed in the center of the perpendicular substrate. This force is measured with a precision balance (Mettler Toledo ML 3002).

\section{Results and Discussion}

\subsection{Influence of the acid concentration and nature}


Chronoamperometry technique was used to modify silicon surfaces by electropolymerization of aniline $(0.4 \mathrm{M})$ from an acid electrolytic solution. The acid used was either a monoacid (hydrochloric acid, $\mathrm{HCl}$, or nitric acid, $\mathrm{HNO}_{3}$ ), a diacid (sulfuric acid, $\mathrm{H}_{2} \mathrm{SO}_{4}$ ) or a triacid (phosphoric acid, $\mathrm{H}_{3} \mathrm{PO}_{4}$ ) at $2 \mathrm{M}$. For all experiments, electropolymerization was carried out for 1 min. After that, adhesion force measurements were performed using an AFM microscope (Figure 1A).
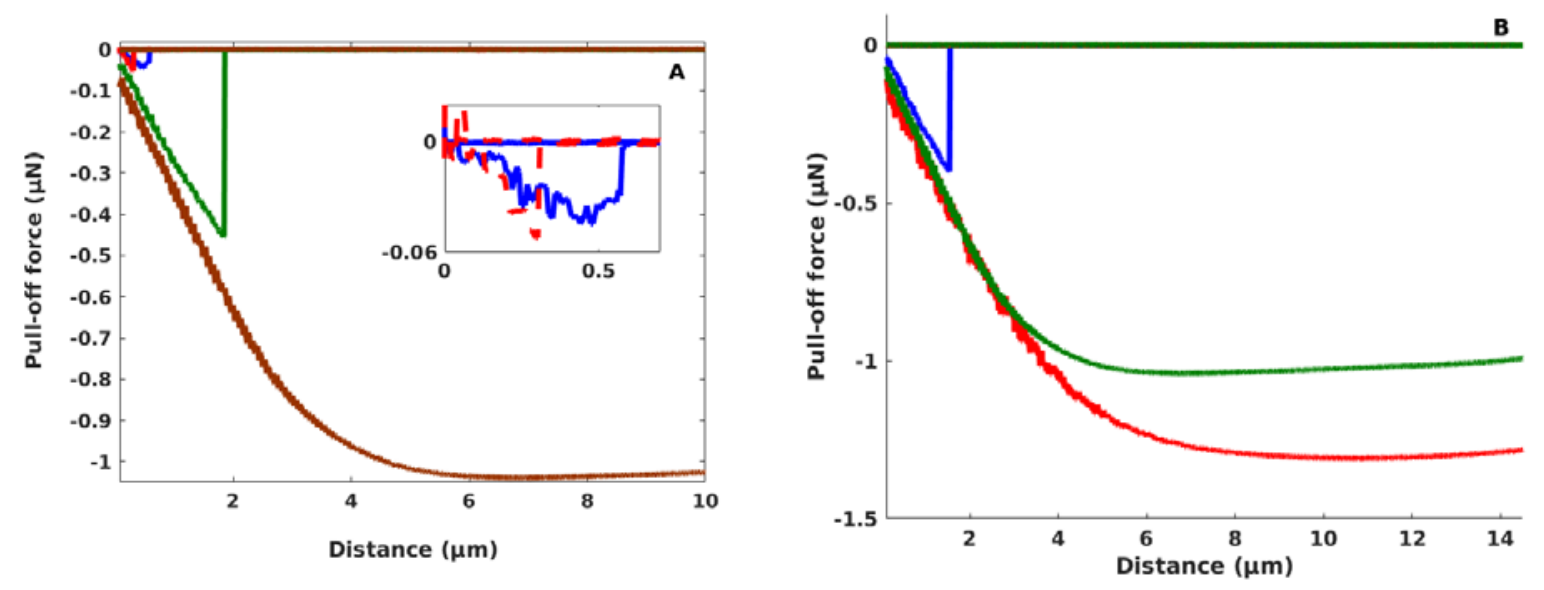

Figure 1. Pull-off forces measurements obtained with polyaniline films prepared: A) in different acid solutions $\mathrm{H}_{3} \mathrm{PO}_{4}$ (brown), $\mathrm{H}_{2} \mathrm{SO}_{4}$ (green), $\mathrm{HNO}_{3}$ (blue) and $\mathrm{HCl}$ (red) concentrated at 2 mol/L; B) $\mathrm{H}_{3} \mathrm{PO}_{4}$ at different phosphoric acid concentration: $2 \mathrm{~mol} / \mathrm{L}$ (red), $1 \mathrm{~mol} / \mathrm{L}$ (green) and $0.5 \mathrm{~mol} / \mathrm{L}$ (blue).

In Figure 1A), it appears that the adhesion forces are significantly different when polyaniline is formed from one acid or another. Indeed, it is noticeable that the adhesive force increases with the number of protons of the acid. More precisely, for a monovalent acid, the pull-off force is around $-50 \mathrm{nN}$ whereas it reaches $-426 \mathrm{nN}$ for $\mathrm{H}_{2} \mathrm{SO}_{4}$ diacid, and less than $-1 \mu \mathrm{N}$ for $\mathrm{H}_{3} \mathrm{PO}_{4}$ triacid. Moreover, for PANi films prepared in phosphoric acid, the exact value of the adhesive force can't be given precisely because an important deflection takes place which saturates the 
sensor. In fact, the conversion of the deflection signal cannot be performed because the sphere stuck to the end of the tip extremity is completely engulfed (see Figure SI-1) in the polymer film, thus confirming the very adhesive character of the $\mathrm{PANi}_{3} \mathrm{H}_{3} \mathrm{PO}_{4}$ film. The value obtained with the monoacid was concordant with values previously obtained by cyclic voltamperometry with $\mathrm{PANi}^{20}$ film or with other conducting polymer such as PEDOT, ${ }^{21}$ polypyrole ${ }^{22}$ or poly(pphenylenediamine). ${ }^{20}$

Since the best results were obtained with $\mathrm{PANI}+\mathrm{H}_{2} \mathrm{SO}_{4}$ and $\mathrm{PANI}-\mathrm{H}_{3} \mathrm{PO}_{4}$ films, the influence of the $\mathrm{H}_{2} \mathrm{SO}_{4}$ and $\mathrm{H}_{3} \mathrm{PO}_{4}$ concentrations was also tested by varying the acid concentrations from $0.5 \mathrm{~mol} / \mathrm{L}$ to $2 \mathrm{~mol} / \mathrm{L}$ (Figure $1 \mathrm{~B}$ and Table 1 ).

\begin{tabular}{|l|l|l|l|l|l|l|}
\hline Acid & $\mathrm{H}_{2} \mathrm{SO}_{4}$ & $\mathrm{H} 3 \mathrm{PO}$ & \\
\hline Concentration (mol/L) & 0.5 & 1 & 2 & 0.5 & 1 & 2 \\
\hline Pull-off (nN) & -29 & -575 & -397 & -411 & $>-1000$ & $>-1500$ \\
\hline
\end{tabular}

Table 1. Influence of the acid concentration on the pull-off force values $(\mathrm{nN})$ (stiffness of the cantilever: $0.3 \mathrm{~N} / \mathrm{m})$.

Figure 1B and Table 1 indicate an increase in pull-off force as the proton concentration increases in the electrolytic solution. Indeed, adhesive forces obtained for polyaniline films electrodeposited in 1 and $2 \mathrm{~mol} / \mathrm{L}$ sulfuric acid (- 575 and - $397 \mathrm{nN}$, respectively) are strongly higher than those obtained in $0.5 \mathrm{~mol} / \mathrm{L}$ sulfuric acid $(-29 \mathrm{nN})$. Similarly, the adhesive forces measured in 1 and $2 \mathrm{~mol} / \mathrm{L}$ phosphoric acid (both $>-1000 \mathrm{nN}$ ) were strongly higher than those obtained in $0.5 \mathrm{~mol} / \mathrm{L}$ solutions $(-411 \mathrm{nN})$. In addition, it can be observed that the adhesion forces measured in phosphoric solutions were greatly higher than those obtained in sulfuric acid whatever the acid concentration. However, the quantity of protons incorporated present in the electrolyte solution is not the only explanation that could be given to explain the difference in the adhesion force values. Indeed, the morphology of the polymer film can also contribute to the 
adhesion behavior of the polymer films. That is why, AFM images of the polymer films grown in phosphoric acid were performed (Figure SI-2) leading to the conclusion that the roughness of the polymer film decreases when the acid concentration increases. This observation is consistent with the literature since it has already been demonstrated that a decrease of the roughness can lead to an increase of the adhesive force, as previously observed with polymer films ${ }^{20,22}$ or structured surfaces. ${ }^{23-25}$ The crystallinity of the polymer films was also studied but all polyaniline films appeared amorphous and no significant difference was observed between the different polymer films (Figure SI-3).

\subsection{Influence of the deposition time}

To determine the influence of deposition time, the most promising polymer film to create adhesion between two surfaces was studied. Thus, polyaniline films obtained from $2 \mathrm{~mol} / \mathrm{L}$ phosphoric acid solutions were prepared by applying a voltage of +2 V/SCE for $10 \mathrm{~s}, 30 \mathrm{~s}, 60 \mathrm{~s}$, $120 \mathrm{~s}$ or $10 \mathrm{~min}$. The adhesion force values and thickness of the resulting polymer films are summarized, in Table 2.

\begin{tabular}{|l|l|}
\hline Deposition time (s) & Pull-off forces (nN) \\
\hline $10 \mathrm{~s}$ & $<-1500$ \\
\hline $30 \mathrm{~s}$ & $<-1500$ \\
\hline $60 \mathrm{~s}$ & $<-1000$ \\
\hline $120 \mathrm{~s}$ & -61 \\
\hline $600 \mathrm{~s}$ & -130 \\
\hline
\end{tabular}

Table 2. Influence of the electrodeposition time on the thickness and pull-off forces values of PANI films grown in $\mathrm{H}_{3} \mathrm{PO}_{4}(2 \mathrm{~mol} / \mathrm{L})$.

Table 2 indicates that the adhesion properties of the polyaniline-modified surfaces are very high for low deposition times but decline when the deposition time increases. The most adhesive surfaces have pull-off forces (greater than $1 \mu \mathrm{N}$ ) which are ten times higher than the less 
adhesive ones. So, the deposition time is an important parameter to obtain adhesive surfaces. In order to correlate the adhesion properties of the films with their morphology, thickness and roughness, the polyaniline-modified surfaces were observed by scanning ion microscopy (SIM) and the thickness of the polyaniline films was measured. For this purpose, the polyaniline films were etched by irradiation using $\mathrm{Ga}^{+}$ions. After focused ion beam (FIB) irradiation, the wafer was tilted and viewed with the scanning ion microscope Figure 2.

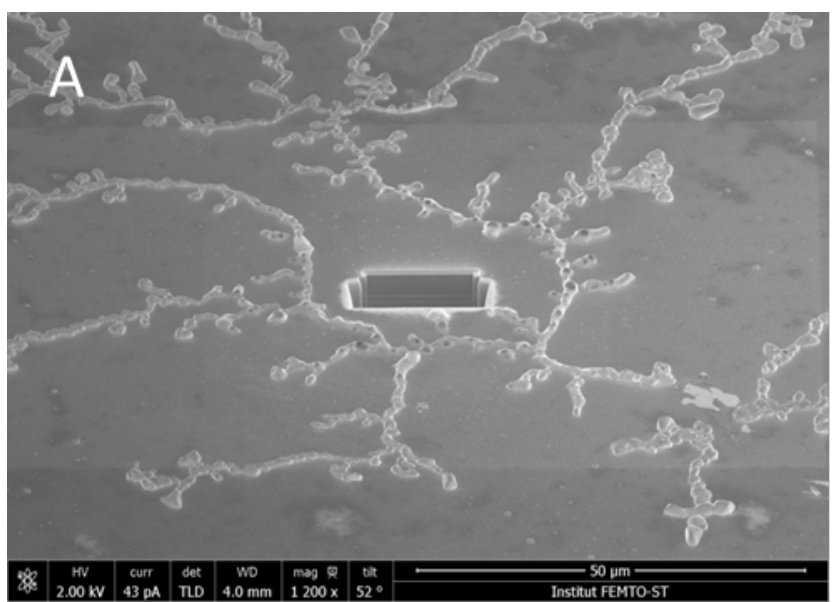

$30 \mathrm{~s}$

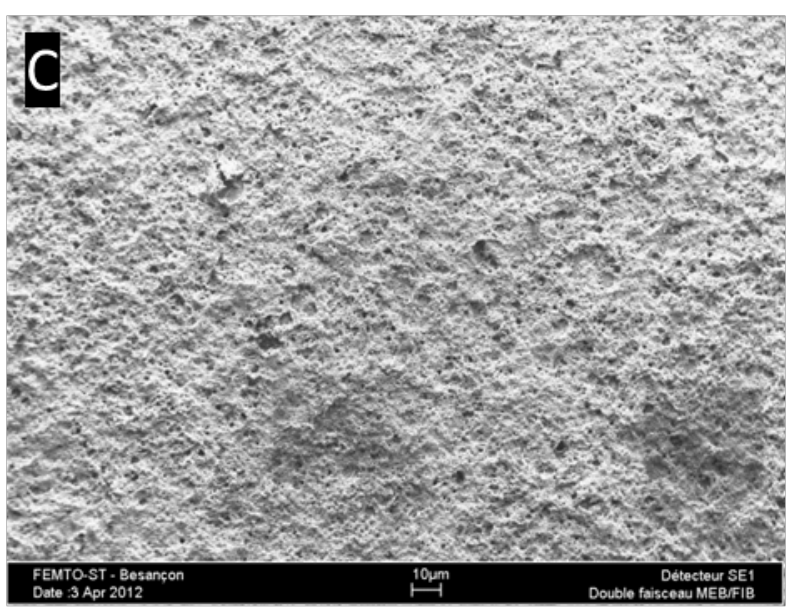

$10 \mathrm{mn}$

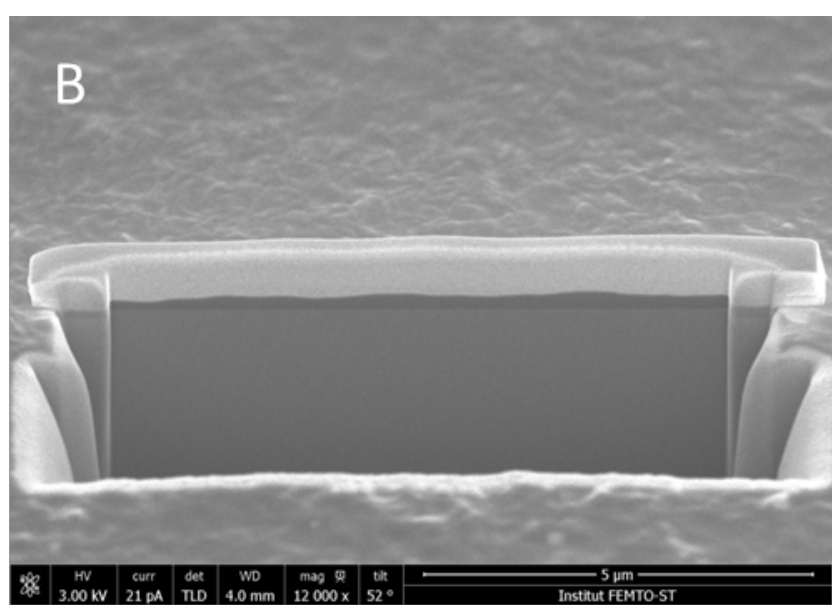

$30 \mathrm{~s}$

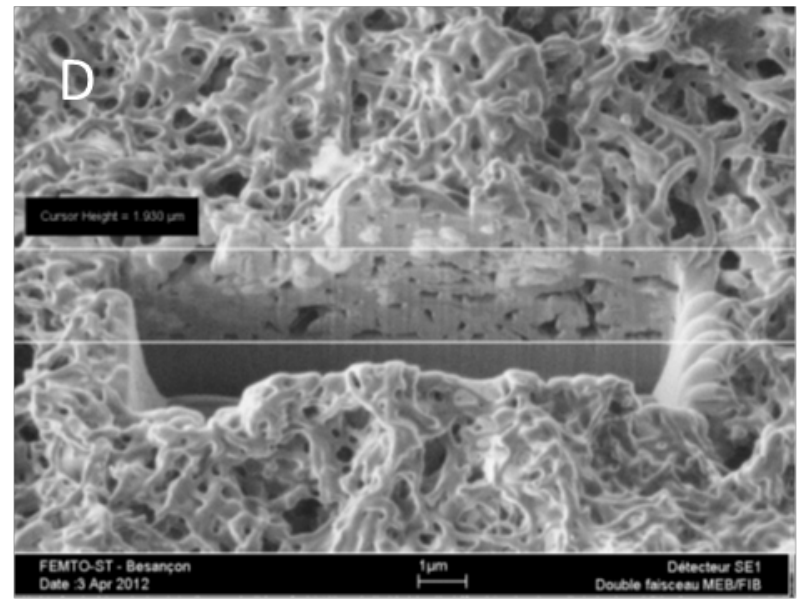

$10 \mathrm{mn}$

Figure 2. SIM images and FIB etching of the PANi-H3PO4 films ([H3PO4] $=2 \mathrm{~mol} / \mathrm{L})$ for different electrodeposition times (30 s and $10 \mathrm{~min}$ ). 
A significant difference in film thickness, morphology and microstructure can be observed in Figure 2. Indeed, a short electrodeposition time, $30 \mathrm{~s}$, corresponds to the beginning of the film growth, therefore the film is not yet structured and looks like a gel and the thickness is $310 \mathrm{~nm}$. The surface is not covered with a homogeneous film but only with short oligomers and nucleation nodules with significant hydration. As the deposition time increases, the chain length of the electrodeposited polymer increases, so the film appears much more structured. Indeed, after $10 \mathrm{~min}$, the thickness $(2250 \mathrm{~nm})$ and the roughness increased with the electrodeposition time which is consistent with an increase in the quantity of PANi deposited on the surface and with a decrease in the adhesive properties. The thickness measured were not unreaslistic with previous studies. Indeed, a thickness range from $75 \mathrm{~nm}$ to $10 \mu \mathrm{m}$ was already measured by cyclic voltamperometry depending on the number of cycle, potential sweep rate, electrolyte and PANi concentration. ${ }^{19,22}$

It has been demonstrated that the adhesive properties of PANi films can be modulated by varying the electrodeposition time and the phosphoric acid concentration.

\subsection{Switching properties and commercial comparison}

Now, it could be interesting to determine whether the adhesion behavior of the polymer film can be easily switched from a low adhesive state to a higher one. That is why, a weakly-adhesive film was prepared from a $0.5 \mathrm{~mol} / \mathrm{L} \mathrm{H}_{3} \mathrm{PO}_{4}$ solution (deposition time: $1 \mathrm{~min}$ ), before being immersed in a $2 \mathrm{~mol} / \mathrm{L} \mathrm{H}_{3} \mathrm{PO}_{4}$ solution for 1,3 and 10 min (Figure 3A). 

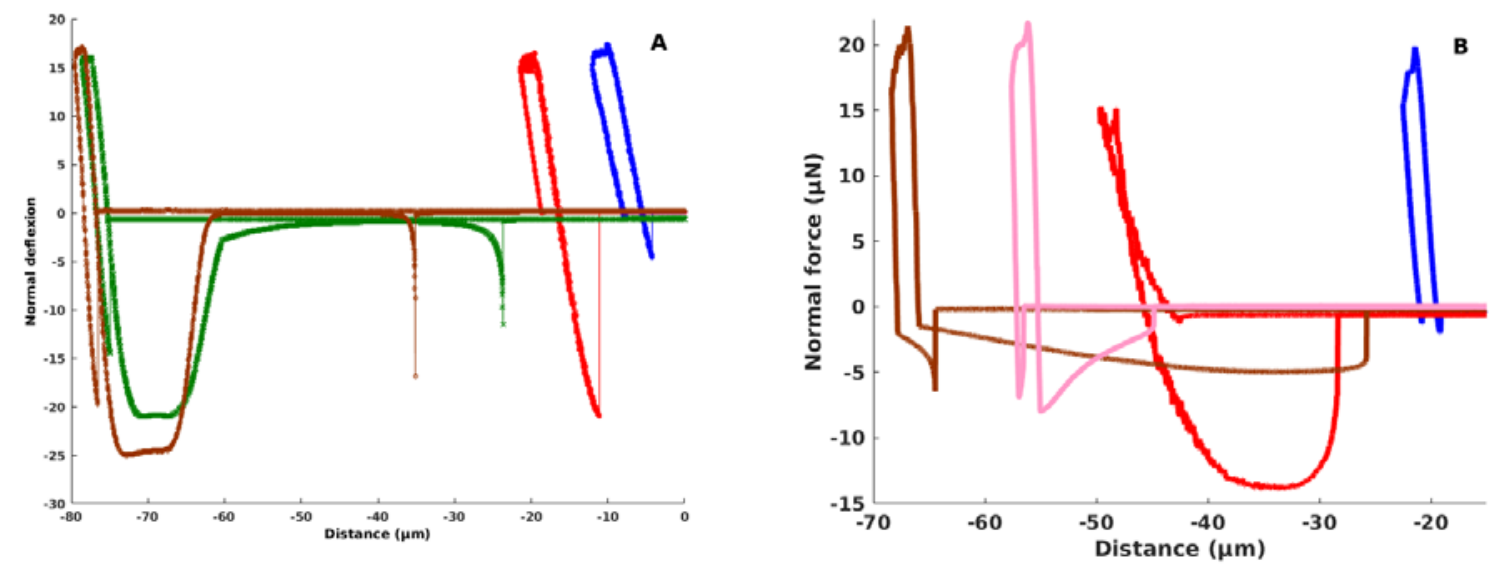

Figure 3. A) Influence of the immersion time in a $2 \mathrm{~mol} / \mathrm{L} \mathrm{H}_{3} \mathrm{PO}_{4}$ solution of the PANi film (electropolymerized during $1 \mathrm{~min}$ in $\mathrm{H}_{3} \mathrm{PO}_{4} 0.5 \mathrm{~mol} / \mathrm{L}$ ): 0s (blue), $1 \mathrm{~min}$ (red), $3 \mathrm{~min}$ (green) and 10 min (brown). B) Comparison of the new adhesive surface $\mathrm{PANi}_{3} \mathrm{H}_{3} \mathrm{PO}_{4}$ with other commercial products: UV Tape (red), $\mathrm{PANi}_{3} \mathrm{H}_{3} \mathrm{PO}_{4} 10 \mathrm{~s}$ (brown), $\mathrm{PANi}_{3} \mathrm{H}_{3} \mathrm{PO}_{4} 1$ min (pink), Gel-Pack (blue).

In Figure 3A, a variation of the force measurement was observed. Indeed, the value of the normal deflexion increases with the immersion time. So the adhesion of the resulting PANi films was so great, after 3 or 10 minutes of immersion. The particular shape of the curve for 3 and 10 minutes of immersion (increasing of the signal and return to zero for a distance close to $-65 \mu \mathrm{M}$ ) was explained by the fact that the laser left the photodiode due to the high adhesion force for the cantilever stiffness. Similarly, the peak observed at $-25 \mu \mathrm{m}$ and $-35 \mu \mathrm{m}$ respectively was due to the return of the laser on photodiode during the dissociation of the cantilever with the PANI film. This time of 3 or 10 min corresponds to the time necessary for the protons and counter-ions to migrate from the solution to the polymer film. 
These results indicate that it is possible to tune the adhesion of the polymer film and thus it can be envisaged to switch reversibly from a non-adhesive to an adhesive state. After that, the adhesive ability of $\mathrm{PANi}_{3} \mathrm{H}_{3} \mathrm{PO}_{4}$ films was compared with commercial materials such as GelPak, which is an UV tape commonly used to glue microelectronic systems, in particular to facilitate their travel and protect them. These AFM force measurements were performed with a cantilever having a stiffness of $14 \mathrm{~N} / \mathrm{m}$ (Figure 3B). The results are promising since the shape of the curves shows that $\mathrm{PANi}_{3} \mathrm{H}_{3} \mathrm{PO}_{4}$ film is more adhesive than the Gel-Pak and only slightly less adhesive than the UV Tape.

\subsection{Tearing force}

To further characterize the adhesion force of the PANi film, experiments were conducted in air to measure the tearing force between two millimeters planes (Figure 4). In this aim, silicon substrates were modified with a $\mathrm{PANi}_{3} \mathrm{H}_{3} \mathrm{PO}_{4}$ film (using the optimal parameters: $2 \mathrm{~mol} / \mathrm{L}$ and 30 s). Two substrates are perpendicular and a third one is deposited perpendicular to the first two. The contact area between the substrates is perpendicular $\left(25 \mathrm{~mm}^{2}\right.$ on each side). 


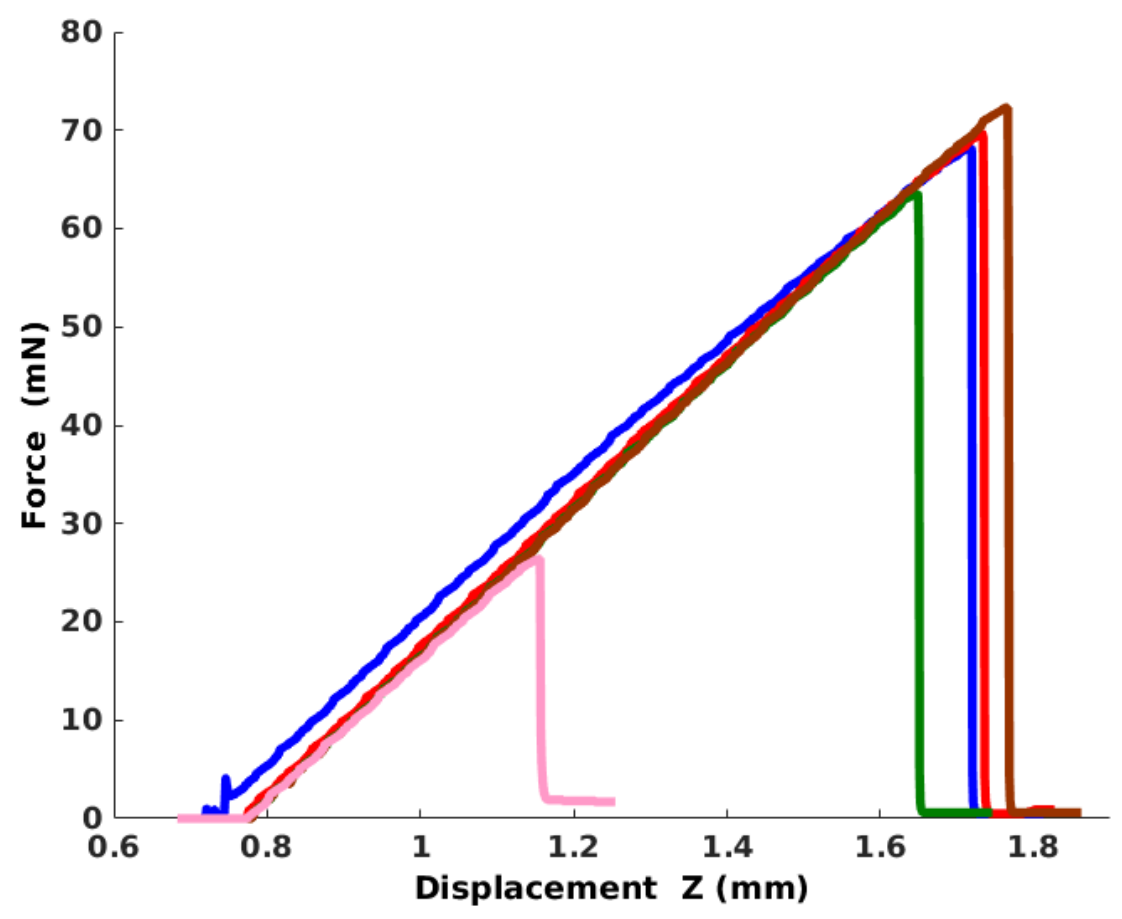

Figure 4. Measurements of peel strength on $\mathrm{PANi}-\mathrm{H}_{3} \mathrm{PO}_{4}$ film (2 mol/L, electropolymerisation time 30s): first (blue), second (red), third (green), fourth (brown) and fifth (pink) test on the same sample.

This experiment led to the measurement of an important peel strength (around $70 \mathrm{mN}$ ). After the measurement, the spacer (third surface perpendicular to the other two) was repositioned in the same place and the experiment was continued until the measured force decreased drastically. Good repeatability of the experiments was noted for the four first experiments. After that, the peel strength decreased. The same result was obtained in repeated trials. $\mathrm{PANi}_{3} \mathrm{H}_{3} \mathrm{PO}_{4}$ films therefore have the property of being both adhesive and repositionable. This last property is of great interest for the manipulation of electronic components before packaging.

\subsection{Applications}




\subsubsection{Micromanipulation}

To validate this new adhesive surface in 3D integration of electronic components, micromanipulation and conductivity tests were performed, Figure 5 (and movie in supporting information).

The surface modified by a $\mathrm{PANi}_{3} \mathrm{HO}_{4}$ film was captured with an air noddle and deposited on another surface. Using this protocol, 6 surfaces were stacked and moved together (Figure 5 and movie). Interestingly, the stacking can be easily deleted by a simple immersion of the whole system in water inducing a separation of the surface.
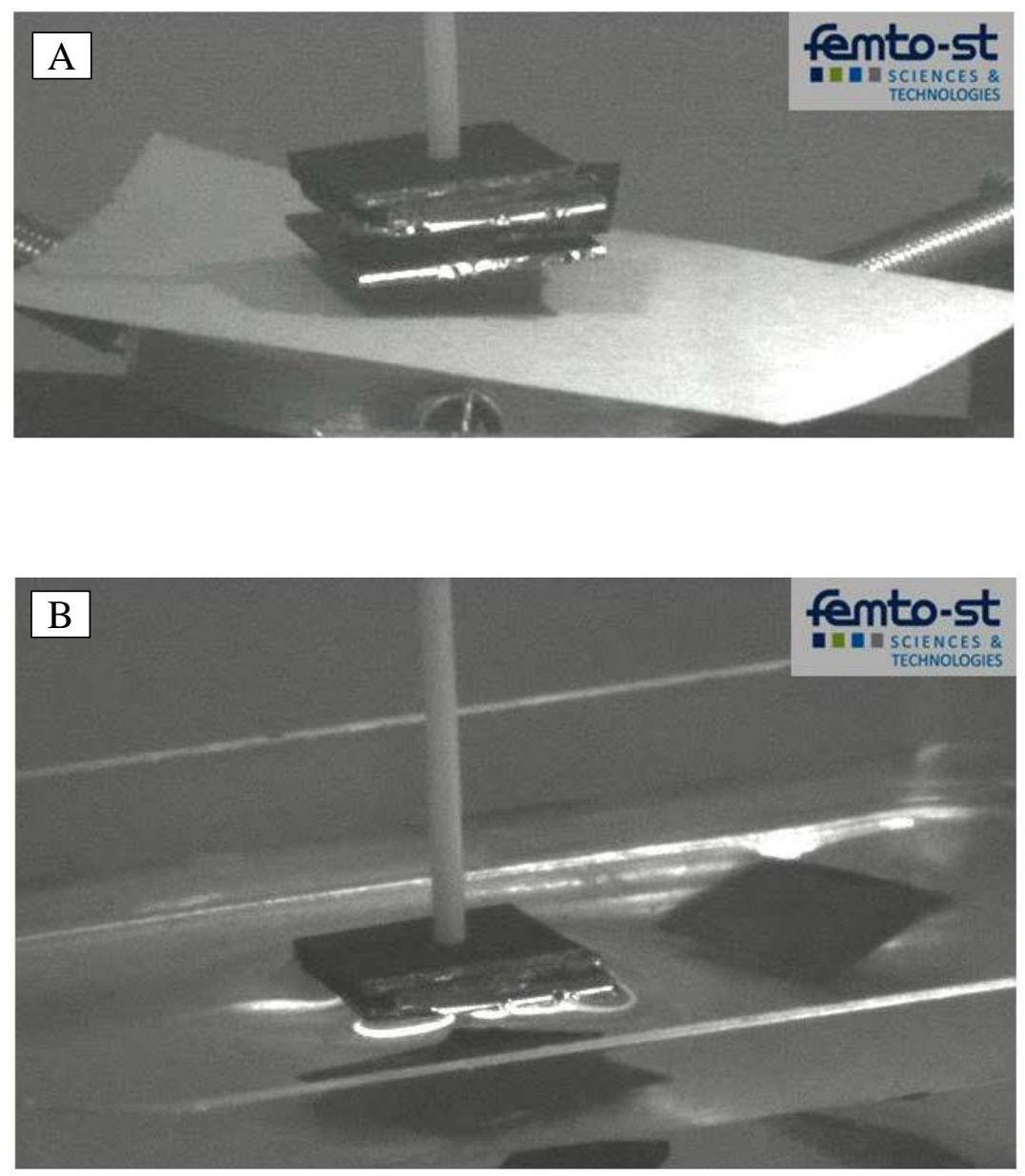
Figure 5. Micromanipulation of surfaces coated by $\mathrm{PANI}-\mathrm{H}_{3} \mathrm{PO}_{4}$ (2 mol/L, 30s): A) catching and moving, B) release.

\subsubsection{Conductivity and assembly}

Usually, PANi electrodeposited films are conductive due to the doping of the polyaniline backbone by counter-anions coming from the electrolytic solution. Since $\mathrm{H}_{3} \mathrm{PO}_{4}$ is rarely used for PANi electrodeposition, it could be useful to check whether the electrodeposited PANi films are doped with the anions obtained by dissolving phosphoric acid in water before measuring the conductivity of PANI- $\mathrm{H}_{3} \mathrm{PO}_{4}$ films. Thus, to evidence the presence of anions in PANi films, Glow Discharge Optical Emission Spectroscopy (GDOES) experiments were performed (Figure SI-4). Whatever the deposition time, the presence of phosphorous elements into the film was demonstrated, thus confirming the doping of the PANi films. The area under the curve corresponding to a PANi film electrodeposited for $10 \mathrm{~s}$ is greater than the one obtained for the curves corresponding to higher electrodeposition times (1 min and $10 \mathrm{~min}$ ). This means that the thinnest film contains the highest amount of anions. Thus, it is believed that the thinnest film is the film with the highest doping level, and it may lead to the highest conductivity. The higher incorporation of anions may also be an additional explanation for the sticky property of the PANi film and may participate in the unstructuring of the film.

After that, the conductivity of PANi-modified FTO (Fluorine doped Tin Oxide) surfaces (grown in $2 \mathrm{~mol} / \mathrm{L} \mathrm{H}_{3} \mathrm{PO}_{4}$ at $2 \mathrm{~V}$ during $10 \mathrm{~s}$ ) was measured using the Van der Pauw procedure (VDP). VDP procedure required four point-like contacts (nickel contacts coated by a thin layer of gold and denoted A, B, C and D) at the edge. In order to obtain the resistivity value of the polymer films, several independent measurements were necessary. Initially, applying the current $\mathrm{I}_{\mathrm{AB}}$ on the contact pair $\mathrm{A}-\mathrm{B}$, the voltage difference $\mathrm{U}_{\mathrm{CD}}$ between the contacts $\mathrm{C}$ and $\mathrm{D}$ was 
measured (the current must be sufficiently small to avoid Joule heating of the sample). It is suitable to repeat this measurement for the opposite current $\mathrm{I}_{\mathrm{AB}}^{\prime}=-\mathrm{I}_{\mathrm{AB}}$ to eliminate voltage contributions whose polarity does not depend on current direction (namely contact potentials). ${ }^{26}$ We also used the FTO because the conductivity surface of the silica was sufficient. For the PANi-H3PO4 film, a value of $1.86 \times 10^{4}{\mathrm{~S} . \mathrm{m}^{-1}}^{-1}$ was measured which is consistent with those already published in the literature. ${ }^{7,27,28}$ Indeed, for a polypyrole film a conductivity between $2 \times 10^{3}$ and $3 \times 10^{5}$ S.m ${ }^{-1}$ was found depending on the monomer concentration, electrolyte salt, potential and area of the deposited film. ${ }^{26}$ The experimental value was also ten and one hundred times higher than the previously PANi film synthesized with $0.4 \mathrm{M}^{28}$ and $2 \mathrm{M}^{27}$ of $\mathrm{H}_{3} \mathrm{PO}_{4}$ respectively. The conductivity on a gold surface functionalized with $\mathrm{PANi}_{3} \mathrm{PO}_{4}$ film was also tested experimentally with two CMS diodes, Figure 6, to demonstrate the application of theses surfaces on the electronic domain. The two diodes were connected between two electrodeposited films. When a potential of $2 \mathrm{~V}$ was applied to the gold substrates coated by the polyaniline film, the CMS diodes switched on, Figure 6B. When no potential was applied the diode switched off, Figure 6A (see also Supporting Information for the movie).
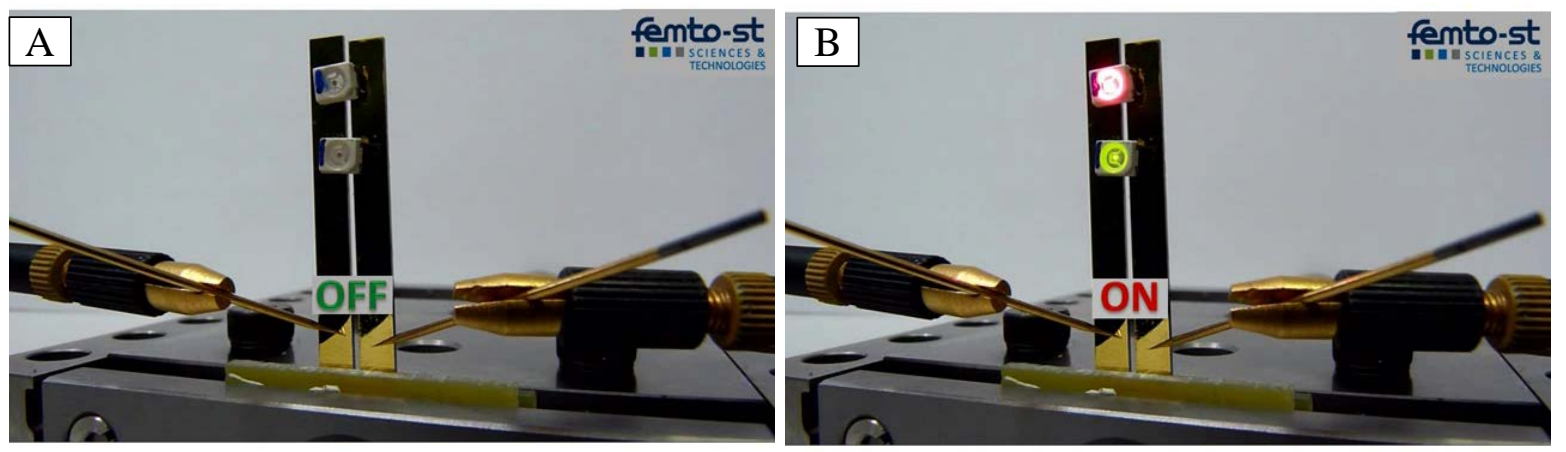

Figure 6. Conductivity test between stabilized and charged CMS diodes using $\mathrm{PANi}_{3} \mathrm{PO}_{4}$ films electrodeposited on gold substrates (2 mol/L, 30s). A) without applying a current and B) with a current applied to the gold film under the polyaniline film. 


\subsubsection{Stability}

So, the polyaniline film developed in this study is highly adhesive, conductive and stable. Concerning this last point, the film was stored in ambient air for a long period (nearly 3 years), and AFM force measurements were performed regularly. No change in the profile of the AFM curve was noticed even after three years. Similarly, the experimental setup, carried out to test the conductivity with CMS diodes, is still efficient, one year after its completion. So, this new film must find its place as a connector and as a conductive adhesive for micro-components. This conductive adhesive could find applications in 3D integration of electronic components since the connections performed were connections between millimeter or submillimeter plans.

\section{Conclusion}

In conclusion, the nano-joining of two micro-objects is possible thanks to a chemical modification of a surface by polyaniline films. This chemical modification is performed by electrochemical polymerization of aniline monomers from phosphoric acid solutions. The electrical and mechanical properties are enough satisfactory to guarantee the conductivity and the junction of micro-objects for applications in microelectronics, for example, and more generally for the assembly and connection of micro-objects. The object can be repositionable 4 times before the properties of the polyaniline film decrease. The reversibility of the link is also possible by immersing the microsystem in an acid solution to increase the adhesion or in ultrapure water to dissolve the film. Moreover, the stability of the film is important since the adhesive forces remain similar after 3 years. In the future, this new polymer film will betested in real conditions, to check the feasibility of its use in industry, in particular as a glue which could allow the assembly of (Bio)MEMS and microcomponents. 


\section{ASSOCIATED CONTENT}

Supporting Information. The following files are available free of charge: Image of the AFM TIP during force spectroscopy on PANI-H3PO4 film, AFM PANI-H3PO4 film morphology, XRay Diffractometry, Glow Discharge Optical Emission Spectroscopy of PANI-H3PO4 as a function of the electrodeposited time, movie of micromanipulation and stacking of 6 surfaces and movie of CMS diodes adhesion and switch on when current applied through this new polymer surface.

\section{AUTHOR INFORMATION}

\section{Corresponding Author}

*Jérôme Dejeu: jerome.dejeu@univ-grenoble-alpes.fr. Give contact information for the author(s) to whom correspondence should be addressed.

\section{Author Contributions}

The manuscript was written through contributions of all authors. All authors have given approval to the final version of the manuscript.

\section{Funding Sources}

EU under FAB2ASM (contract FoF-NMP-2010-260079), Région Franche-Comté (contract 2011C-07333)

\section{ACKNOWLEDGMENT}

The authors acknowledge Dr. V. Moutarlier (Université Bourgogne Franche-Comté, UTINAM Institute, UMR CNRS 6213) and Dr. R. Salut (Université Bourgogne Franche-Comté, FEMTO- 
ST Institute, UMR CNRS 6174) for assistance (respectively Glow Discharge Optical Emission Spectroscopy and SIM/FIB experiments). This work was supported by the EU under FAB2ASM (contract FoF-NMP-2010-260079): Efficient and Precise 3D Integration of Heterogeneous Microsystems from Fabrication to Assembly, by Région Franche-Comté under FIMICAP (contract 2011C-07333): Fiabilisation du microassemblage et mise au point de capteurs intelligents par ingénierie des surfaces.

\section{REFERENCES}

(1) Hu, X.; Stow, D.; Xie, Y. Die Stacking Is Happening. IEEE micro, 2018, 38, 22-38. https://doi.org/10.1109/MM.2018.011441561

(2) Yang, P.; Wang Y.; Deng, L. A review on reliability of electronic packaging in micro/nano manufacturing. Int. J. Mat. \& Struct. Integrity, 2015, 9, 131-143. https://doi.org/10.1504/IJMSI.2015.071114

(3) Qin, I.; Yauw, O.; Schulze, G.; Shah, A.; Chylak, B.; Wong, N. Advances in Wire Bonding Technology for 3D Die Stacking and Fan Out Wafer Level Package in proc. of IEEE 67th Elec. Comp. \& Tech. Conf, 2017. https://doi.org/10.1109/ECTC.2017.134

(4) Ye, N.; Li, Q.; Zhang, H.; Ji, Z.; Yang, X.; Chiou,C.-T.; Takiar, H. Challenges in Assembly and Reliability of Thin NAND Memory Die. In proc. of IEEE 66th Elec. Comp. \& Tech. Conf, 2016. https://doi.org/10.1109/ECTC.2016.226

(5) Trivedi, D. In Handbook of Organic Conductive Molecules and Polymers; Nalwa, H., Ed.; Wiley, 1997; Vol. 2. 
(6) Stejskal, J.; Gilbert, R. Preparation of a Conducting Polymer. Pure Appl. Chem. 2002, 74, 857-867. https://doi.org/10.1351/pac200274050857

(7) Boara, G.; Sparpaglione, M. Synthesis of Polyanilines with High Electrical Conductivity. Synth. Met. 1995, 72, 135-140. https://doi.org/10.1016/0379-6779(94)02337-X

(8) Prokes, J.; Stejskal J. Polyaniline Prepared in the Presence of Various. Acids: 2. Thermal Stability of Conductivity. J. Polym. Degrad. Stab. 2004, 86, 187-195. https://doi.org/10.1016/j.polymdegradstab.2004.04.012

(9) Trchova, M.S.; Sedenkova, I.; Tobolková E.; Stejskal, J. FTIR Spectroscopic and Conductivity Study of the Thermal Degradation of Polyaniline Films. J. Polym. Degrad. Stab. 2004, 86, 179-185. https://doi.org/10.1016/j.polymdegradstab.2004.04.011

(10) Peng, X.Y.; Luan, F.; Liu, X.X.; Diamond, D.; Lau, K.T. pH-Controlled Morphological Structure of Polyaniline during Electrochemical Deposition. Electrochimica Acta 2009, 54, 6172-6177. https://doi.org/10.1016/j.electacta.2009.05.075

(11) Plesu, N.; Kellenberger, A.; Mihali, M.; Vaszilcsin, N. Effect of Temperature on the Electrochemical Synthesis and Properties of Polyaniline Films. J. Non-Crystalline Solids 2010, 356, 1081-1088. https://doi.org/10.1016/j.jnoncrysol.2010.01.011

(12) Moo, J.G.S.; Mayorga-Martinez, C.C.; Wang, H.; Khezri, B.; Teo, W.Z.; Pumera, M. Nano/Microrobots Meet Electrochemistry. Advanced Functional Materials 2017, 1604759. https://doi.org/10.1002/adfm.201604759 
(13) Gao, W.; Sattayasamitsathit, S.; Orozco, J.; Wang, J. Highly Efficient Catalytic Microengines: Template Electrosynthesis of Polyaniline/Platinum Microtubes. J. Am. Chem. Soc. 2011, 133, 11862-11864. https://doi.org//10.1021/ja203773g

(14) Ramanaviciene, A.; Viter, R.; Ramanavicius, A.; Deshmukh, M.A.; Shirsat , M.D.; Gicevicius, M. Towards Electrochemical/Electrochromic Sensors Based on Polyaniline Modified Indium Tin Oxide Electrodes. In proceeding of the 2017 IEEE International Conference on Nanomaterials: applications and properties, Odessa, Ukraine, September 10-15, 2017, 03NNSA32-1 - 4. https://doi.org/10.1109/NAP.2017.8190276

(15) Kharade, R.R.; Patil, P.B.; Khot, K.V.; Ghanwat, V.B.; Kondalkar, V.V.; Bagade, C.S.; Desai, N.D.; Mane, R.M.; Bosale, P.N. Controlled Electrochemical Polymerization Strategies for Electroactive Polyaniline Thin Films. Macromol Symp 2016, 362, 7-10. https://doi.org/10.1002/masy.201400262

(16) Turemis, M.; Zappi, D.; Giardi, M.T.; Basile, G.; Ramanaviciene, A.; Kapralovs, A.; Ramanavicius A.; Viter, R. ZnO/Polyaniline Composite Based Photoluminescence Sensor for the Determination of Acetic Acid Vapor. Talanta, 2020, 211, 120658. https://doi.org/10.1016/j.talanta.2019.12065

(17) German, N.; Popov, A.; Ramanaviciene, A.; Ramanavicius, A. Formation and electrochemical characterisation of enzyme-assisted formation of polypyrrole and polyaniline nanocomposites with embedded glucose oxidase and gold nanoparticles. J. Electrochem. Soc., 2020, 167, 165501. https://doi.org/10.1149/1945-7111/abc9dc

(18) Popov, A.; Brasiunas, B.; Damaskaite, A.; Plikusiene, I.; Ramanavicius, A. ; Ramanaviciene, A. Electrodeposited gold nanostructures for the enhancement of electrochromic 
properties of PANI-PEDOT film deposited on transparent electrode. Polymers, 2020, 12, 2778. https://doi.org/10.3390/polym12122778

(19) Popov, A.; Brasiunas, B.; Mikoliunaite, L.; Bagdziunas, G.; Ramanavicius, A. ; Ramanaviciene, A. Comparative Study of Polyaniline (PANI), Poly(3,4-ethylenedioxythiophene) (PEDOT) and PANI-PEDOT Films Electrodeposited on Transparent Indium Thin Oxide based Electrodes. Polymer, 2019, 172, 133-141. https://doi.org/10.1016/j.polymer.2019.03.059

(20) Cot, A. ; Lakard, S.; Dejeu, J. ; Rougeot, P. ; Magnenet, C. ; Lakard, B. ; Gauthier, M. Electrosynthesis and Characterization of Polymer Films on Silicon substrates for Applications in Micromanipulation. Synthetic Metals 2012, 162, 2370-2378. https://doi.org/10.1016/j.synthmet.2012.11.023

(21) Lupu, S.; Lakard, B. ; Hihn, J.-Y.; Dejeu, J.; Rougeot, P. ; Lallemand, S. Morphological characterization and analytical application of poly(3,4-ethylenedioxythiophene)-Prussian blue composite films electrodeposited in situ on platinum electrode chips. Thin Solid Film, 2011, 519, 7754-7762. https://doi.org/10.1016/j.tsf.2011.06.011

(22) Dejeu, J.; Taouil, A. E.; Rougeot, P.; Lakard, S.; Lallemand, F. ; Lakard, B. Morphological and Adhesive Properties of Polypyrrole Films Synthesized by Sonoelectrochemical Technique. Synthetic metals 2010, 160, 2540-2545. https://doi.org/10.1016/j.synthmet.2010.10.002

(23) Dejeu, J.; Bechelany, M.; Berodier, E.; Rougeot, P.; Michler, J.; Gauthier, M. Nanostructured Nonadhesive Surfaces for Micro- and Nanomanipulation. The Journal of Physical Chemistry C 2012, 116, 15117-15125. https://doi.org/10.1021/jp303414c 
(24) Heim, L.-O.; Blum, J.; Preuss, M.; Butt, H.-J. Adhesion and Friction Forces between Spherical Micrometer-Sized Particles. Physical Review Letters 1999, 83, 3328-3331. https://doi.org/10.1103/PhysRevLett.83.3328

(25) Dejeu, J.; Bechelany, M.; Rougeot, P.; Philippe, L.; Gauthier, M. Adhesion Control for Micro- and Nanomanipulation. ACS Nano 2011, 5, 4648-4657. https://doi.org/10.1021/nn200658z

(26) Patois, T.; Lakard, B.; Martin, N.; Fievet, P. Effect of various parameters on the conductivity of free standing electrosynthesized polypyrrole films. Synthetic Metals 2010, 160, 2180-2185. https://doi.org/10.1016/j.synthmet.2010.08.005

(27) Ayad, M.M.; Salahuddin, N.A.; Alghaysh, M.O.; Issa, R.M. Phosphoric Acid and pH Sensors based on Polyaniline Films. Current Applied Physics 2010, 10, 235-240. https://doi.org/10.1016/j.cap.2009.05.030

(28) Blinova, N.V.; Stejskal, J.; Trchova, M.; Prokes, J. Polyaniline Prepared in Solutions of Phosphoric Acid: powders, Thin Film, and Colloidal Dispersions. Polymer 2006, 47, 42-48. https://doi.org/10.1016/j.polymer.2005.10.145

Graphical abstract 


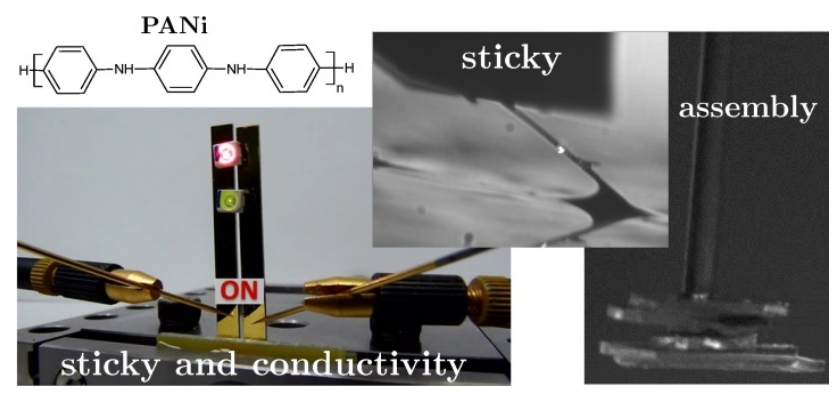

